\title{
The EKG in cardiac MRI: what the technologist needs to know
}

\author{
Emer Sonnex, Richard Coulden \\ From 17th Annual SCMR Scientific Sessions \\ New Orleans, LA, USA. 16-19 January 2014
}

\section{Background}

In routine cardiac MRI (CMRI) practice, radiological technologists are expected to optimize and utilize EKGs in gating and physiological monitoring. Many cardiac sequences are critically dependent on heart rate and rhythm and EKG gating problems lead to poor or nondiagnostic images. The technologist's syllabus does not routinely include formal EKG recognition or CMRI trouble-shooting techniques.

\section{Methods}

In this educational exhibit, we describe common EKG rhythms and discuss imaging parameter options for overcoming magneto-hemodynamic effects, dealing with high or low heart rates and abnormal rhythms.

\section{Results}

An image sequence/EKG rhythm quick algorithm is included for reference and will be the basis of the exhibit.

\section{Conclusions}

Basic EKG rhythm recognition and imaging optimization tips are the building blocks of good cardiac MRI something every good CMRI technologist should know but are rarely formally taught.

\section{Funding}

None.

Published: 16 January 2014

Department of Radiology \& Diagnostic Imaging, University of Alberta Hospital, Edmonton, Alberta, Canada

C Biomed Central
doi:10.1186/1532-429X-16-S1-T4

Cite this article as: Sonnex and Coulden: The EKG in cardiac MRI: what the technologist needs to know. Journal of Cardiovascular Magnetic Resonance 2014 16(Suppl 1):T4.
Submit your next manuscript to BioMed Central and take full advantage of:

- Convenient online submission

- Thorough peer review

- No space constraints or color figure charges

- Immediate publication on acceptance

- Inclusion in PubMed, CAS, Scopus and Google Scholar

- Research which is freely available for redistribution 


\section{Quick algorithm for successful EKG gating in CMR}

Normal sinus rhythm: $60 \rightarrow 99 \mathrm{bpm}$ (optimize segments/views per segment -15 to 9 respectively) Sinus bradycardia: $<60 \mathrm{bpm}$ - increased acquisition time (increase numbers of segments from 15) Sinus tachycardia: > 99bpm - decreased acquisition time (decrease number of segments from 9 ) 1degree AV block: heart rate dependence only (as above)

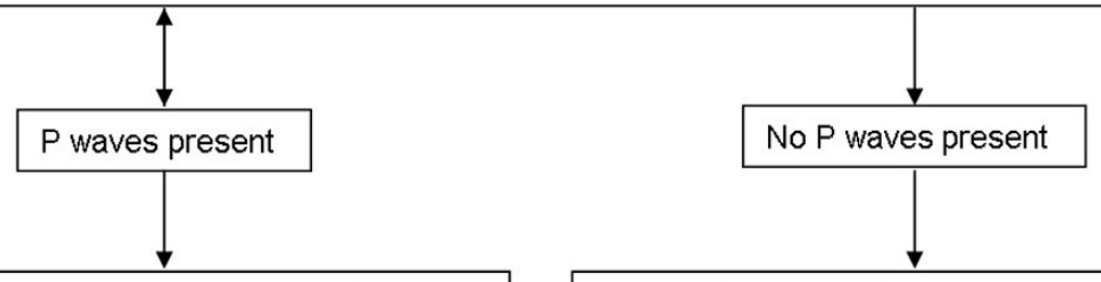

Sinus rhythm with prolonged QRS (>0.1s) left bundle or right bundle branch blocks. No influence on imaging acquisition (heart rate dependence only).
Atrial fibrillation (AF) - irregularly irregular rhythm, no $P$ waves.

If rate fluctuation is $<20$, use prospective triggering.

If rate fluctuation is $>20$, use prospective triggering with increased acceleration factors to decrease acquisition times (GRAPPA 3, etc). Consider also reducing resolution to decrease acquisition times.

If rate fluctuation exceeds 40 , you may need to use real time imaging.
AV Blocks - regular $R-R$ intervals $2^{\text {nd }}$ degree Type $\|-2: 1$ block. Slow ventricular rate - treat as bradycardia and increase number of segments $3^{\text {rd }}$ degree - treat as bradycardia and increase number of segments.

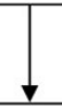

AV Blocks - irregular $R-R$ intervals $2^{\text {nd }}$ degree Type I - treat as AF and use prospective triggering $2^{\text {nd }}$ degree Type II - treat as AF and use prospective triggering

\section{ECTOPY:}

Occasional premature ectopy - use retrospective gating + arrhythmia rejection. Set rejection window time (ms) to exclude beats that are premature (eg $200 \mathrm{~ms})$. Eg. Heart $=60 \mathrm{bpm}$, set acceptance window $=1000 \mathrm{~ms}$. All beats falling outside $50-70 \mathrm{bpm}$ will be rejected.

Frequent ectopy (bigeminy/trigeminy) use finger plethysmography for pulse gating/triggering (depending on regularity of underlying rhythm). Review that peripheral pulse does not read the ectopy. Use retrospective pulse gating and increase segments to compensate for underlying bradycardia. Remember that diastole will occur several phases later in pulse gating (peripheral vs systemic pulse).

Last resort: real time imaging. Use gated real time and trigger off sinus beat, not ectopic beat. 